\title{
La legislación (nacional y bonaerense) sobre riberas y humedales conexos
}

\author{
Leonardo Fabio Pastorino y Juan Carlos Acuña \\ Proyecto J11/169 - Cátedra I Derecho Agrario - Facultad de Ciencias Jurídicas y Sociales (UNLP). \\ E-mail: mpastorino@jursoc.unlp.edu.ar
}

RESUMEN. El trabajo se inicia con una descripción de los criterios propios del derecho, que influyeron en la lógica de sus disposiciones en relación con los bienes de la naturaleza en general y del agua en particular y que explican cómo, aún hoy, las categorías dominiales influyen, interfieren y obstaculizan la adopción de una concepción ecosistémica. Se sintetiza el cuadro dominial de las aguas y los criterios adoptados para la definición de las riberas, considerando las novedades introducidas con el Código Civil y Comercial en 2015 y cómo esas disposiciones se continúan en el Código de Aguas de la Provincia de Buenos Aires y otras normas derivadas del mismo.

Palabras clave: Agua, humedales, legislación, riberas, ríos.

ABSTRACT. The work begins with a description of the criteria specific to the law that influenced the logic of its regulations in relation to the goods of nature in general and water in particular and that explain how, even today, the domain categories influence, interfere and hinder the adoption of an ecosystem conception. The water domain regime and the criteria adopted for the definition of the riverbanks are synthesized, considering the novelties introduced with the Civil and Commercial Code in 2015 and how those regulations continue in the Water Code of the Province of Buenos Aires and other derived rules.

Keywords: Legislation, riverbanks, rivers, water, wetlands. 


\section{Breve reseña del abordaje del agua por el derecho}

Tradicionalmente, en el derecho occidental y desde los romanos, si no antes, la naturaleza y sus bienes fueron considerados "cosas" y "objeto" de las relaciones jurídicas. El derecho los trató especialmente a partir de cada uso que de ellos fueron haciendo las poblaciones y fundamentalmente, cuando esos usos generaron conflictos derivados por su escasez (Pastorino, 2005). Así, Cano (1979) sostenía que las primeras normas que se ocuparon de ciertos recursos naturales se refirieron a su propiedad y a su uso. Aquellos bienes considerados superabundantes, en relación a la cantidad de habitantes, pudieron gozar de una categoría jurídica especial, como las res communis, cosas comunes destinadas al aprovechamiento común, pero no necesariamente al cuidado común (Francario, 1990).

Los ríos fueron también vistos como cosas, incluso, cosas inmuebles, "cuerpos" (Marienhoff, 1939), meros conductos de agua en circulación. Cobraron interés para la localización de las ciudades, por el preciado don del agua, también útil para el hombre y como vía fácil de comunicación. También sirvieron de límites entre estados, divisiones, fronteras y defensas, poniendo un obstáculo a las relaciones analizadas desde la óptica sospechosa de la competencia y la guerra. No se reconocía ni el ciclo del agua, ni las características particulares y dinámica de este recurso, ni el régimen hidrológico, ni sus funciones ecosistémicas.

Respecto al agua también se la vio siempre con relación a su utilidad para el hombre. Por su importancia y relativa escasez, por cuestiones naturales o por necesitar de obras para que esté a disposición de los usuarios, se reguló el uso pero también el dominio, buscando a través de esta institución poder distribuirla entre todos. Con modelos diferentes, más justos unos de otros pero todos imperfectos, se puso al agua siempre como objeto de la relación dominial (Pastorino, 2009), con el incremento consecuente de las tensiones y disputas por su apropiación.
El derecho clásico reguló sobre los bienes de la naturaleza desde la perspectiva de la titularidad del dominio y la regulación de su uso y aprovechamiento y hoy esa estructura jurídica perdura y continúa influyendo a pesar de que se genera una corriente de cambio a favor de la conservación, la concepción ecosistémica y la armonización de las actividades del hombre con la perdurabilidad del planeta.

En este contexto es que aparece el poco interés existente en el derecho argentino por las riberas, fundamentalmente tratadas para delimitar los espacios públicos (como ríos, lagos y playas) de los privados. Tampoco se puede dejar de mencionar una connatural mirada antropocéntrica del derecho que es creado por y para regular las relaciones entre los mismos seres humanos y su creación y evolución, también sigue las perspectivas que la humanidad siguió siendo el derecho argentino aun mayormente tributario de una concepción desarrollista. En esta última perspectiva debe mencionarse que expresa o tácitamente el sistema jurídico y el accionar público consintieron y hasta promovieron una cantidad de obras, alteraciones y artificialización de las riberas $y$, por el contrario, encontramos pocos antecedentes de preocupaciones normativas por el respeto y cuidado de las mismas o que tomen nota de su valor ecosistémico.

A partir de los años '80 y más fuertemente en la Argentina luego de la reforma de 1994, se incorpora una visión más integral de los recursos bajo el concepto de ambiente y se empieza a definir un nuevo enfoque que presta mayor atención a las interrelaciones con instrumentos como la evaluación de impacto ambiental, y principios como el de precaución y el de prevención que empiezan a diseñar un nuevo derecho que deja la mirada utilitaria sobre los recursos.

\section{Las aguas en la legislación nacional}

A nivel nacional tenemos unas cuantas competencias para legislar en materia de aguas (Pastorino, 2017). Pero para ir directamente al punto que nos convoca de las riberas $y$, en 
particular, aquellas vinculadas a la Provincia de Buenos Aires, debemos centrarnos en el Código Civil y Comercial. Este cuerpo normativo basal para nuestro derecho sustituyó al Código Civil que desde 1871 dispuso sobre el dominio de las aguas, definiendo cuáles son públicas, cuáles privadas y cuáles de posible apropiación. Allí entra un concepto bastante primitivo y poco o nada fundado en el conocimiento hidrológico que veía, como vimos, a estas aguas como cuerpos (lagos, ríos, mares) incluso a veces calificadas de "durmientes" dando aún más la idea de inmovilidad y fácil delimitación (Pastorino, 2009).

Por otra parte, el paradigma imperante de la época era el que favorecía la propiedad privada y el Código Civil, fundamentalmente reservado a las cuestiones entre los particulares, entraba a definir los bienes públicos con la sola intención de delimitar el amplio marco de los bienes que podrían ser objeto de apropiación (López, 1987). En tal sentido, el art. 2347 disponía que todos los bienes que no se definían como del Estado nacional o de las provincias o de los municipios o de la Iglesia, corresponderían a los privados. El Código de Vélez sólo comprendía como "bienes públicos del Estado General o de los estados particulares" (las provincias) a "los ríos y sus cauces $y$ todas las aguas que corren por cauces naturales" (art. 2340 inc.3); la reforma por Ley 17.711 introduce, a este artículo e inciso, sustanciales modificaciones disponiendo que son bienes del dominio público “...Los ríos, sus cauces, las demás aguas que corre por cauces naturales y toda otra agua que tenga o adquiera la aptitud de satisfacer usos de interés general, comprendiéndose las aguas subterráneas, sin perjuicio del ejercicio regular del derecho del propietario del fundo de extraer las aguas subterráneas en la medida de su interés y con sujeción a la reglamentación". Así y todo, no se reconoce ningún tipo de conexión entre las llamadas aguas superficiales con las llamadas subterráneas. También cabe hacer notar que, con la mención a los ríos, la doctrina interpretó incluido en ese concepto a toda agua que corre por cauce natural, sin entrar en distinciones hidrogeológicas o científicas. Así, se considera como si fueran ríos los arroyos, riachos, arroyuelos, etc. (López, 1987).

En este contexto es que surge el concepto de "línea de ribera" para dividir el dominio público del dominio privado (Mathus Escorihuela, 2007) que va a tener directrices para su delimitación diferentes en el caso del mar y de los ríos, pero que, por el ámbito geográfico que estamos tratando vamos a obviar para concentrarnos en aquella de los ríos. Para adoptar una directriz en tal demarcación, la doctrina recurrió al art. 2577 del Código Civil, el que, al hablar del aluvión toma como criterio para incluir en el concepto de dominio público del río a la línea a la que llegan "las más altas aguas en su estado normal", incluyendo los aumentos de nivel de las aguas debidos a causas de carácter permanente, doctrina del plenissimun flumen (Mathus Escorihuela, 2007). Pero la citada reforma de la ley 17.711 introdujo un cambio en el art. 2340 inc. 4, por el cual se incluyeron en el dominio público las riberas internas de los ríos "entendiéndose por tales la extensión de tierra que las aguas bañan o desocupan durante las altas mareas normales o las crecidas medias ordinarias". Al no modificarse el art. 2577 quedó plasmada una incongruencia que dio de hablar por varios años a la doctrina. También ello llevó a cuestiones judiciales y batallas por apropiarse de terrenos aluvionales (Lamoglia, 2018).

Finalmente, el Código Civil y Comercial sigue con la inclusión de la definición de las aguas públicas en su interior, retoca en parte el esquema del Código Civil sin dejar de introducir alguna mirada más novedosa como la de ver el agua con su dinámica y con su ciclo y, por ende, termina dejando sin resolver cuestiones tan necesarias como, por ejemplo, la de los humedales (Pastorino, 2017). A modo de síntesis del cuadro dominial fijado en el actual sistema, se definen:

A. Aguas de dominio público:

a) El mar territorial, con una derivación a la ley especial que lo determina, como en el Código derogado, pero con el agregado que incluye "el agua, el lecho y el subsuelo".

b) Las aguas interiores, bahías y ensenadas y las playas de mar que el código define como la porción de tierra que las mareas bañan y desocupan durante las más altas y más bajas 
mareas normales. Agrega luego un texto de difícil interpretación cuando a dicha definición la cierra con la frase "y su continuación hasta la distancia que corresponda de conformidad con la legislación especial de orden nacional o local aplicable en cada caso".

c) Los ríos, estuarios, arroyos y aguas que corren por cauces naturales. Aquí confunde al agregar arroyo, porque antiguamente se interpretaba que no era necesaria una definición geográfica o hidrológica que distinga entre río, arroyo, torrente, canal, etc., siendo que se incluía toda agua que corre por cauces naturales. Al sumar arroyo alguien podría querer interpretar que otros cursos no podrían haberse querido incluir. El Código define al río considerando en él "el agua, las playas y el lecho por donde corre, delimitado por la línea de ribera que fija el promedio de las máximas crecidas ordinarias. Deja entonces la distinción para delimitar la playa del río por el promedio de máximas crecidas ordinarias, cuando para la playa de mar tiene en cuenta la más alta marea normal. Por otra parte, deja la situación del Río de la Plata, en lo que hace a la definición de su playa, como un río más, cuando la legislación bonaerense (art.18 decreto 3511/08) buscaba asimilar más su situación a la definición dada para playa de mar.

d) Los lagos y lagunas navegables. Acá agrega laguna, que antes se entendía como incluida en el concepto de lago, importando si este era navegable o no. Deja la definición de navegable, como hacía el Código anterior, a la interpretación. Más allá de las distintas opiniones doctrinarias, pongo de relieve una reciente sentencia que vale la pena traer a colación por la jerarquía de la instancia. Se trata de la Suprema Corte de Justicia de la Provincia de Buenos Aires, que debiendo tratar el tema de la navegabilidad o no (esta vez de un río para determinar la titularidad de un terreno aluvional, art. 2572 del derogado Código Civil) hizo hincapié al hecho notorio de la navegación (SCBA, 12-3-14, causa B 50865). Es decir, la calidad de navegable o no la acreditarían los hechos, la realidad y no el calado (como era antes de la ley 17.711) o aptitud para navegar en abstracto, lo que suma otro dislate porque el bien podría cambiar de régimen dominieal por una simple práctica o desarrollo de la actividad, como también podría perder el carácter por el abandono de la misma práctica.

e) Incluye en una misma redacción dos supuestos que se consideraban diferentes y que ahora parecen estar definidos en relación de género y especie. Me refiero a la inclusión de "toda otra agua que tenga o adquiera la aptitud de satisfacer usos de interés general, comprendiéndose las aguas subterráneas, sin perjuicio del ejercicio regular del derecho del propietario del fundo de extraer las aguas subterráneas en la medida de su interés y con sujeción a las disposiciones locales. Este artículo no resuelve las dudas que generaban esas dos hipótesis en el Código derogado (Pastorino et al., 2013).

f) Los glaciares y el ambiente periglaciar. Queda ahora el desafío de determinar el límite de dicho ambiente periglaciar y discutir los criterios para hacerlo, materia de no poco relevante interés ambiental y económico ya que, a lo que se caracterice como ambiente periglaciar le corresponde una nueva dominialidad pública y las restricciones a las actividades productivas impuestas por la antes mencionada ley de presupuestos mínimos de protección de glaciares y ambiente periglaciar.

El artículo 239 agrega la regla que el uso por cualquier título de aguas públicas u obras construidas para utilidad o comodidad común, no les hace perder el carácter de bienes públicos del Estado, siendo inalienables, imprescriptibles, inenajenables e inembargables.

Como dijimos, nuevamente quedaron sin definición los esteros y otros cuerpos de agua o humedales de importancia que, por el artículo 238 , quedan atrapados en la propiedad privada. Ello obliga a pensar su protección desde la óptica de las restricciones de actividades siempre tan difíciles de imponer en modo general para un país tan vasto, cuestión que, seguramente influye en la imposibilidad hasta el presente de contar con una ley de presupuestos mínimos de protección ambiental de los humedales.

B. Aguas privadas:

a) Aguas que surgen en terrenos de los particulares. Así seguirían con una redacción apenas alterada. Los privados titulares de los fundos las pueden usar libremente siempre 
que no se forme un cauce natural. Estas aguas, no obstante, quedan sujetas al control y a las restricciones que en interés público establezca la autoridad de aplicación. También se agrega la regla de que no pueden ser usadas en perjuicio de terceros ni en mayor medida de su derecho (art.239). Quedaría también la posibilidad que con una declaración particular se establezca el cumplimiento de un interés general en cada caso en concreto y se puedan expropiar.

b) Los lagos no navegables. El art. 236 inc. c, lo determina a contrario sensu al disponer que éstos son de dominio privado del Estado, siempre que no tengan dueño (privado). En realidad, esta disposición que poco fue explicada por los autores del nuevo Código plantea una modificación a una vieja dificultad interpretativa en el Código Civil con respecto a si los propietarios linderos a estos lagos eran propietarios por la parte correspondiente a su lindero o si simplemente tenían, como la norma expresaba, un derecho al uso. El problema es que, si se hacía interpretación literal, solo tendrían un derecho al uso y quedaba indefinida su titularidad, puesto que tampoco el Código Civil los enunciaba como públicos y, muy por el contrario, parecía excluirlos al especificar que sí eran públicos aquellos navegables. Por otra parte, el dominio público requiere ser definido taxativamente por la norma. Ante esta indefinición, otros interpretaban que tenían el uso común de todo el lago y la propiedad hasta los límites de su inmueble (López, 1987). Sobre la base de estas dudas es posible que muchos lagos o lagunas no navegables fueran inscriptos junto a sus inmuebles en los registros de propiedad. Hoy, los herederos de la postura que creía ver en ellos una dominialidad estatal, ven esta norma como un retroceso ya que el dominio del Estado sería del tipo de dominio privado y susceptible a la privatización definitiva del lago, mientras que, para la postura que los veía en una indefinición, el nuevo régimen puede constituir un avance, a la vez que sirve para consolidar la propiedad privada de muchos de ellos, los que ya fueron registrados.

Aquí no se optó por agregar las lagunas que, por su dimensión, suelen ser las que puedan ser menos navegables. Seguramente habrá que seguir la vieja interpretación que las incluía en el concepto de lago, pero manifiesta un error de técnica legislativa cuando en el dominio público se especifican como cosas diferentes.

C. Aguas del dominio privado del Estado:

a) Los lagos no navegables que no son privados.

b) Todas las aguas que existan en inmuebles del dominio privado del estado.

D. Aguas sin dueño (res nullius):

Sigue siendo sin dueño, pero susceptible de apropiación. el agua de lluvia que cae en lugares públicos o corre por ellos (art. 1947, a, iii).

Ahora retomando el tema de las riberas de ríos, lagos y lagunas públicos, el Código Civil y Comercial en su art. 235 menciona entre aquellas a "los ríos, estuarios, arroyos y demás aguas que corren por cauces naturales" (inc. c) pero aclara en el mismo inciso que se "entiende por río el agua, las playas y el lecho por donde corre, delimitado por la línea de ribera que fija el promedio de las máximas crecidas ordinarias". El mismo inciso incluye en el dominio público a los lagos y lagunas "navegables" y establece que se entiende por lago o laguna al "agua, sus playas y su lecho, respectivamente, delimitado de la misma manera que los ríos".

La redacción actual supone la superación de las dificultades, en la delimitación del dominio público de la del dominio privado de las franjas de tierra ocupadas por las crecidas de los cursos de las aguas, que emergían de la redacción anterior del artículo 2340 inc. 4 identificando como ribera la ocupación de tierras por las aguas durante las "crecidas medias ordinarias", concepto que colisionaba con la del artículo 2577 que fijaba como límite de los ríos el que resultara de "las más altas aguas en su estado normal".

\section{La línea de ribera en el Código de Aguas de la Provincia de Buenos Aires}

A pesar de varios intentos a lo largo de la historia de la Provincia (Pastorino, 2014), el Código de Aguas fue sancionado recién en 1 os últimos días de 1998 y, no obstante comprender un enfoque bastante más amplio, integral y con una mirada unicista respecto al recurso, no puede dejar de reconocer el esquema dominial previsto en el Código Civil y sus instituciones. En pos de la coherencia en el tratamiento 
del tema, mencionaremos las disposiciones sobre la línea de ribera primero, para seguir el hilo del tratamiento con respecto a aquel cuerpo normativo nacional. Luego algunas cuantas disposiciones del Código de Aguas y de la Autoridad por él creada que pueden tener alguna importancia en la protección de estas, ante las modificaciones recurrentes realizadas tanto por sujetos privados como entes públicos y otras restricciones impuestas en relación a llanuras de inundación y cartas de riesgo hídrico. Ante el criterio rígido del Código Civil y del actual Código Civil y Comercial que pretende una delimitación tajante espacial entre lo que puede pertenecer al dominio público y privado, corresponde cuestionarse la concordancia de la línea de ribera con respecto a la dinámica ecosistémica, ante escenarios de excesos hídricos y aumentos de caudales, desbordes de cursos naturales o artificiales cuya "normalidad" oscilará según transcurra en una "fase húmeda" o una "fase seca" de las que experimenta la ecorregión pampeana desde que se tiene registro desde hace más de siglo y medio. Lo que puede ser ribera en una "fase seca" puede ser cauce en una "fase húmeda". La ocupación hídrica y, consecuentemente, la ampliación del cauce puede ser instantánea o prolongada en el tiempo, todos estos factores son producidos por la naturaleza, si bien puede concederse que en muchos casos converge la obra humana. Estas situaciones ponen en conflicto no sólo la delimitación territorial de un ecosistema acuático, del que las riberas forman parte, sino también la delimitación entre el dominio público y el dominio privado de parcelas rurales colindantes a cursos naturales o artificiales de aguas.

La consideración precedente nos coloca ante la evidencia que las líneas de riberas no son "permanentes", son fluctuantes por acción combinada de la naturaleza y obras hidráulicas, factores que incorporan obstáculos para el diseño y acción de eventual recuperación o restauración de las riberas para la protección del ecosistema acuático.

Ello, no obstante, a nivel normativo la delimitación de la línea de ribera y los criterios para realizarla están previstos en el artículo 18 del Código de Aguas que expresa: "la Autoridad del Agua fijará y demarcará la línea de ribera sobre el terreno, de oficio o a instancia de cualquier propietario de inmuebles contiguos o de concesionario amparados por el Código de Aguas. Si la demarcación se realizare de oficio, será a cargo del Estado y si lo fuere a petición de parte, a su exclusivo cargo. Se considerará crecida media ordinaria a aquella que surja de promediar los máximos registrados en cada año durante los últimos cinco años. A falta de registros confiables se determinará conforme a criterios hidrológicos, hidráulicos, geomorfológicos y estadísticos evaluados a la luz de una sana y actualizada crítica.

De este artículo se deriva que corresponde a la Autoridad del Agua la delimitación, lo que en la práctica hará con participación de la Fiscalía de Estado, organismo de la Constitución provincial previsto para la tutela del interés público. También surge que puede hacerse a instancia de parte o de oficio, es decir, por decisión de la propia autoridad. En la práctica, muchas veces son los particulares que, en miras a un trámite de usucapión o exigencias de tipo administrativas, instan a la delimitación por la parte en que el río colinda con su terreno, lo que desde ya nos indica una labor por demás inconclusa, parcial y discontinua. También reafirma la directriz de tomar las crecidas medias ordinarias pero avanza en sintetizar este criterio a través de un promedio de los máximos registrados de cada año de los últimos cinco años, decisión que también hace referencia a una fluctuación que puede influir, por un lado, en el aceleramiento o desinterés por delimitar la línea de ribera en un momento dado y, por el otro lado, en situaciones de zozobra de parte del privado o de los intereses colectivos, algunos años posteriores a la delimitación, por las características propias de nuestra Provincia con períodos de inundaciones y sequías mucho más amplios. Esto pretende ser solucionado por el art. 21 del Código de Aguas que dispone que "cuando la línea de ribera cambiase por causas naturales o acto legítimo, la Autoridad del Agua procederá a una nueva fijación y demarcación", claro que tal disposición deja algunas dudas desde el punto de vista jurídico a la luz de la doctrina de los derechos adquiridos. Finalmente, en caso de no haber datos estadísticos, se 
invocan criterios hidrológicos, geomorfológicos e hidráulicos, que deberán ser evaluados en base a una sana y actualizada crítica. Es de notar que no se mencionan criterios biológicos o ecológicos. Respecto a la actualización de la práctica y actualización en base a criterios, es de mencionar que se realizan periódicamente congresos sobre el tema línea de ribera, impulsados por el Consejo Hídrico Federal el que nuclea a las autoridades en materia de agua de todas las provincias.

Luego de aproximadamente 10 años, el Código fue reglamentado. El decreto 3511/07 nos aporta algunas cuestiones importantes. En primer lugar, define qué se entiende por línea de ribera como "una sucesión de puntos que determinan las altas mareas normales o las crecidas medias ordinarias" (art. 18). A continuación, el decreto introduce una vía para poder considerar otros criterios científicos al decir que para la fijación "la Autoridad del Agua utilizará, además de la serie indicada en el párrafo tercero del artículo, todas las series hidrométricas confiables y disponibles, representativas del comportamiento hidráulico, y toda la información y la metodología académicamente aceptada, necesaria para obtener la fijación de la línea de ribera más exacta posible" (art. 18). Resulta también importante señalar que el decreto reglamentario incluye una norma de protección de la ribera al disponer en su artículo 21 que en "el supuesto de alteraciones de la línea de ribera que no tenga origen en causas naturales o en acto legítimo, corresponderá declarar la clandestinidad de lo obrado e intimar al propietario o responsable a la realización de los trabajos necesarios para restituir, a su costa, las cosas a su estado natural o anterior" disposición, por otra parte, coherente con el art. 41 de la Constitución Nacional que introdujo el criterio de la recomposición del daño ambiental. Luego de publicado el decreto y ratificados los criterios establecidos en el Código y su reglamentación, Cadenazzi (2007) recuerda que el por entonces Ministerio de Infraestructura, Vivienda y Servicios Públicos, dictó la resolución 705/07 para el procedimiento de "declaración de la existencia", definición y demarcación de la línea de ribera y visación de planos de mensura, tramite este último de competencia de tal ministerio pero que requiere la previa demarcación de la línea. En la resolución se autoriza a recurrir al asesoramiento de organismos públicos e instituciones académicas y/o de investigación nacionales y/o provinciales con incumbencia en la materia, a los efectos de realizar los estudios necesarios para la determinación técnica de la línea de ribera, en los casos que así se estime conveniente.

El entrecomillado a la declaración de existencia lo hemos agregado nosotros en virtud que lo interesante que señala el autor de esta resolución es contemplar un supuesto poco tratado por la doctrina hasta ese entonces y referido a lo que la resolución llama "situaciones mínimas, donde el agua existente no satisface usos de interés general". En la lógica de la disposición se contempla el supuesto de aguas que, sin haber sido taxativamente incluidas por el Código Civil como del dominio público por formar "cuerpos" definidos (mares, ríos, lagos y lagunas, etc.) podrían entrar en esa categoría dominial por ser aptas para satisfacer necesidades de interés general. Allí la resolución ejemplifica con situaciones tales como "aguas sin cauce identificable en el terreno, cursos efímeros o intermitentes, líneas de escurrimiento, vaguadas, bañados, humedales, pantanos, aguas estancadas temporalmente". Para esos casos, la resolución plantea que, previamente, la Autoridad defina si son aguas que tengan o adquieran la aptitud de satisfacer usos de interés general (en consonancia con el antiguo art. 2340 inc. 3, definición hoy reiterado a en el art. 235 inc. 3), situación que debería analizarse en cada caso concreto puesto que, si dichas aguas hubieran sido ya contempladas dentro de la propiedad privada, tal declaración debería funcionar como una declaración particular de interés general que habilite la expropiación (Pastorino et al., 2013). La resolución dispone que, en caso de no declararse por acto administrativo del Directorio de la Autoridad del Agua dicho estado de interés general, no corresponde la delimitación de la línea de ribera.

También representa de interés para nuestra temática la apelación de la resolución a la ley 6253 , que quedó vigente como cuerpo normativo de importancia en el derecho de aguas de la Provincia (junto con la 5965 relativa a la contaminación y la 6254 que prohíbe 
fraccionamientos en zonas inundables, entre otras). La ley 6253 crea zonas de conservación de los desagües naturales a cada lado de los ríos, canales, arroyos y en todo el perímetro de las lagunas, estableciendo una medida de 50 metros en cursos y 100 metros en lagos y lagunas, a partir, precisamente, de la línea de ribera, donde rige una restricción a la propiedad privada, prohibiéndose variar el uso actual de la tierra y permitiéndose sólo ejecutar las obras y accesorios que sean necesarias para su actual destino o explotación.

\section{Otras disposiciones del Código de Aguas y de la Autoridad del Agua útiles para la protección de riberas}

CComo se ha señalado, el Código de Aguas rige el recurso a partir de un criterio de unicidad (Pastorino, 2014). En tal sentido, al intentar abarcar el gobierno de todas las aguas y de todas las actividades que pueden afectarlas, posee disposiciones útiles para prevenir cualquier afectación a las riberas. Como regla general puede decirse que toda obra que afecte la dinámica del agua requiere permiso o concesión previos de la Autoridad del Agua, la que deberá hacer las evaluaciones técnicas pertinentes. Además:

1) Al mandar a la Autoridad del Agua a confeccionar cartas de riesgo hídrico prohíbe en las zonas que puedan ser afectadas por inundaciones, obras, plantaciones u otros obstáculos sin previa autorización de la Autoridad del Agua en las mismas (art. 6). Es de hacer notar que, previamente al Código de Aguas, para cartas de riesgo ya se había sancionado una ley más específica y aún vigente, 11.964 , la que, además, obliga a realizar la evaluación de impacto ambiental en las obras a ejecutar. En zonas de riesgo o evacuación de inundaciones, el Poder Ejecutivo puede establecer restricciones referidas a "edificar o modificar construcciones de determinado tipo"; reglamentar los usos de los inmuebles y sus accesorios; habitar o transitar en zonas de riesgo inminente (art. 156). La ley 11.964 expone una preocupación por las manifestaciones de los fenómenos ambientales que trascienden los límites artificiales del dominio o de derechos en general. También expresa, capaz en forma incompleta, una visión de interrelaciones y dinámicas ecosistémicas, tanto al obligar a incorporar a la zonificación áreas protectoras de fauna y flora silvestre como a realizar una evaluación de impacto ambiental de las obras y trabajos a ejecutar.

2) En caso de otorgar permisos para la ocupación de cauces, lechos, vasos o álveos, la Autoridad del Agua podrá requerir un estudio de impacto ambiental (arts. 34 y 44). Pero en general, fuera de estos casos específicos, la Autoridad del Agua considerará cuáles actividades generan riesgo o daño al agua o al ambiente y exigirá la EIA, conteniendo el Código algunas disposiciones complementarias para los mismos, más allá de las disposiciones generales de la ley 11.723, tales como la exigencia de contemplar y evaluar "distintas alternativas" (arts. 97 y ss.).

3) En caso de obstrucción natural del escurrimiento, la Autoridad del Agua puede obligar al propietario a remover los objetos que la generan o a permitir el acceso para la limpieza (art. 137).

4) Se reitera la prohibición de modificar el uso de la tierra en una franja de 50 metros de ríos y canales a fin de conservar los desagües naturales (art. 143).

Pero también en el Código se autoriza a los dueños de predios que linden con cauces públicos a defender sus márgenes contra "la fuerza del agua", mediante endicamientos marginales o atacarrepuntes, plantaciones o revestimientos que pueden situarse aún en la ribera; pero deben obtener permiso de la Autoridad del Agua con quince días de antelación, e incluso, la Autoridad puede mandar a suspender tales operaciones y aún restituir las cosas a su estado anterior cuando ello amenace causar un perjuicio (art. 96).

Se puede pensar, de la lectura del Código y del nombre que éste le dio a su autoridad de aplicación, que todo queda en manos de una fuerte autoridad omnipresente en el vasto territorio provincial, uno de los más antropizados, urbanizados y utilizados del país. Pero en un análisis en profundidad de la eficacia del Código, la aparente contundencia de sus 
disposiciones podría ser puesta en duda.

También son dignas de consideración algunas resoluciones de la Autoridad del Agua, entre las que pueden citarse la Resolución 229/02 de canales y obras clandestinas, que autoriza a denunciarlos y establece un procedimiento para la intervención de la Autoridad del Agua tendiente a restablecer el estado anterior.

Por otra parte, también con relación a las riberas en el territorio bonaerense debe mencionarse el decreto 1072/18 que establece un procedimiento para la convalidación de cambios de uso del suelo y aprobación de conjuntos inmobiliarios (barrios cerrados y clubes de campo) en forma electrónica; el que ordena los pasos a seguir a través de los distintos organismos provinciales involucrados. Fundamentalmente, lo que procura el decreto es dar un trámite común y ordenado a las intervenciones de la Dirección Provincial de Ordenamiento Urbano y Territorial del Ministerio de Infraestructura y Servicios Públicos, actualmente dentro del Ministerio de Gobierno, autoridad de aplicación provincial del decreto - ley 8912/77; de la Autoridad del Agua, organismo autárquico pero dentro del Ministerio de Infraestructura, por cuanto la misma tuvo desde su creación a partir de la sanción del Código de Aguas, intervención en los fraccionamientos de tierras urbanas y suburbanas para vivienda en cuanto a la necesidad de analizar la factibilidad de agua potable en las mismas (art. 173 del Código de Aguas), pero que también, en el devenir del desarrollo de proyectos como los descriptos de mega urbanizaciones que modifican los espacios acuáticos y humedales y el normal escurrimiento del agua, la convocaron como autoridad de aplicación del Código en cuanto no pueden realizarse alteraciones de este tipo sin su previa aprobación y, finalmente, del Organismo Provincial para el Desarrollo Sostenible (OPDS) por su necesaria intervención para evaluar ambientalmente tales proyectos y dictar la correspondiente declaración de impacto ambiental.

\section{Algunas otras normas provinciales de interés}

No obstante, lo dicho respecto al Código de
Aguas que somete a un control, autorización y evaluación de obras por parte, preferentemente, de los privados, el mismo Código mantuvo la vigencia de la ley 10.106 que establece un "Régimen General en Materia Hidráulica", texto actualizado con las modificaciones de las leyes $10.385,10.988$ y $2.307 / 99$. Esta norma regula los estudios, anteproyectos, proyectos, ejecución y financiación de obras de drenaje rurales; desagües pluviales urbanos; dragado y mantenimiento de cauces en vías navegables; dragado de lagunas u otros espejos de agua y su sistematización, así como cualesquiera otros trabajos relacionados con el sistema hidráulico provincial. El art. 4 de la ley 10.106 dispone que la conservación, modificación y reconstrucción de gálibos de los canales principales de drenaje y de los cursos de aguas naturales que abarquen más de un partido estará a cargo de la Provincia. Mientras, el artículo 14 de la ley 10.385 creó un Fondo estatal para financiarlos.

El art. 3 de la ley 10.106 autoriza a delegar en los municipios el poder de policía hasta los límites de capacidad de los cuerpos receptores que a juicio de la misma no comprometan el normal funcionamiento de los sistemas de drenaje zonal y total.

\section{CONCLUSIONES}

El derecho miró desde sus orígenes los conflictos y sus soluciones en la búsqueda de un objetivo superior, como la paz social. Reguló siempre interviniendo en las actividades humanas y se interesó por las motivaciones propias de los hombres. En esa lógica, los recursos naturales fueron objeto de apropiación y uso. En materia de aguas, la legislación, como en tantos otros aspectos, deriva de normas del derecho romano y sus criterios se consolidan con el paso del tiempo y su aceptación. Los fenómenos ambientales fueron siempre difíciles de interpretar y el derecho les aplicó sus reglas. Las cuestiones dominiales, es decir la clasificación de los bienes de acuerdo con su titular o dueño, se definen en el ordenamiento argentino en el Código Civil a partir de competencias otorgadas en la Constitución y que las provincias no pueden soslayar. Por eso se ha descripto 
primero el cuadro nacional para luego ver en ese contexto cómo las normas provinciales regulan los fenómenos concretos que suceden en su territorio.

La línea de ribera es el instituto jurídico principal para poder definir lo público y lo privado y, con ello, distintas modalidades de intervención del derecho. Bajo una concepción aún muy amplia y casi absoluta del derecho de propiedad, imponer restricciones a favor de conceptos científicos, se hace todavía muy difícil.

Ello, no obstante, se ha visto que para la definición de la línea de ribera la legislación provincial reconoce la dinámica del recurso. Adopta criterios hidrológicos y geomorfológicos, además de las mediciones de las crecidas del agua, previstas en el Código Civil, en cuanto en el mismo terreno pueden tomarse datos o vestigios del alcance de tales crecidas. En cambio, la normativa no hace referencia expresa a manifestaciones biológicas o ecológicas, como podrían derivarse de la presencia de ciertas poblaciones de plantas, criterios que sí se receptan como válidos en distintos proyectos de leyes de humedales. A pesar de ello, las normas provinciales admiten que la Autoridad del Agua puede recurrir a toda metodología académicamente aceptada y a recurrir al asesoramiento de organismos públicos e instituciones académicas y/o de investigación nacionales y/o provinciales con incumbencia en la materia.

Más allá de la delimitación de la línea de ribera, resulta por demás necesario dar cumplimiento con la ley 11.964 porque esta manda establecer la definición y la demarcación, en el terreno y en la cartografía y la preparación de mapas de zonas de riesgo que incluyan diferentes zonas con prohibiciones totales, más severas y parciales, según el riesgo. Para ello, el rol de la ciencia es fundamental y debe analizarse la situación en forma holística e interdisciplinaria tratando de comprender la dinámica ecosistémica. En esas áreas, las restricciones no serán ni acotadas ni establecidas en base a reglas arbitrariamente establecidas para toda la Provincia sin distinción de diferencias, como la citada medida de 50 metros a partir de la ribera para evitar construcciones, seguramente condicionada por el criterio de no alterar el derecho de propiedad.
Claro que, avanzar en base a la ley 11.964 abarcando extensiones más amplias requiere de mucha más decisión política, comprensión de los valores en riesgo, tanto naturales como materiales como humanos $y$, seguramente, será más probable si se utiliza una metodología participativa y de búsqueda de consensos con los propios destinatarios asentados o con propiedades en las áreas de riesgo.

\section{REFERENCIAS}

Cadenazzi, A. (2009). La línea de ribera. Procedimiento para su definición y demarcación ante situaciones de mínima concurrencia de agua. En: Pastorino, L. (Dir.). El agua (pp. 367 381). Buenos Aires: Ediciones Cooperativas y Facultad de Ciencias Jurídicas y Sociales de la Universidad Nacional de La Plata.

Cano, G. (1979). Recursos naturales y energía. Derecho, política y administración. Buenos Aires: Fondo Editorial de Derecho y Economía.

Francario, L. (1990). Danni ambientali e tutela civile. Napoli: Jovene.

López, J. (1987). El derecho federal de aguas en la legislación federal argentina. Anales de la Academia Nacional de Derecho y Ciencias Sociales de Córdoba, XXVI, 23-72.

Marienhoff, M. (1939). Régimen y legislación de las aguas públicas y privadas. Buenos Aires: Abeledo Perrot.

Mathus Escorihuela, M. (2007). Las clases de agua y su regulación. En: Mathus Escorihuela, M. (Dir.). Derecho y administración de aguas (pp. 83-102). Mendoza: Edición propia.

Lamoglia, C. M. (2018). La línea de ribera y el aluvión desde la legislación y su tratamiento en la jurisprudencia. En: Pastorino, L. F. (Dir.). Las formas de la naturaleza y sus formas de regulación (pp. 161-170). Buenos Aires: Ediciones Cooperativas y Facultad de Ciencias Jurídicas y Sociales de la Universidad Nacional de La Plata.

Pastorino, L. F. (2005). El daño al ambiente. Buenos Aires: Lexis Nexis. 
Pastorino, L. F. (2009). El agua y las categorías jurídicas. En: Pastorino, L. (Director). El agua (pp. 19-40). Buenos Aires: Ediciones Cooperativas y Facultad de Ciencias Jurídicas y Sociales de la Universidad Nacional de La Plata.

Pastorino, L. F (2014). Código de Aguas de la Provincia de Buenos Aires. En: Pastorino, L. F. (Coordinador). De códigos y desafíos jurídicos para enfrentar la crisis del agua (pp. 23-56). Buenos Aires: Ediciones Cooperativas y Facultad de Ciencias Jurídicas y Sociales de la Universidad Nacional de La Plata.
Pastorino, L. F (2017). Una visión panorámica del derecho del agua. Revista Iberoamericana de Derecho Ambiental y Recursos Naturales, 24. Recuperado en: https://ar.ijeditores.com/pop. php? option $=$ articulo $\&$ Hash $=e 479520777 c 4442 e c$ 6ddcdfd14442a16 (fecha de acceso: 13-08-2020)

Pastorino, L., Cenicacelaya, M. y Diloreto, A. (2013). Régimen de dominio de las aguas subterráneas y consecuencias para su gestión, protección, tutela y aprovechamiento. En: , González, N., Kruse, E. E., Tovatto, M. M. y Laurencena, P. (Eds.). Agua subterránea, recurso estratégico. Tomo 1. (pp. 259-266). La Plata: Edulp. 